\title{
DIABETIC FOOT ULCERS; CORRELATION OF NUTRITIONAL STATUS OF TYPE 2 DIABETIC PATIENTS OF HYDERABAD SINDH PAKISTAN.
}

1. FCPS, Professor of Medicine Liaquat University of Medical and Health Sciences Jamshoro Sindh, Pakistan.

2. MD, Associate Professor of Medicine Liaquat University of Medical and Health Sciences Jamshor Sind, Pakistan.

3. $\mathrm{DCH}$, Senior lecturer, LUMHS Jamshoro.

4. Research Officer,

Medical Research Center Liaquat University of Medical and Health Sciences Jamshoro Sind, Pakistan.

\section{Correspondence Address:}

Dr. Imran Ali Shaikh

Professor of Medicine

Liaquat University of Medical and Health Sciences Jamshoro.

A -81, Qasim Nagar, Qasimabad.

Hyderabad, Pakistan.

imran2naila@yahoo.com

Article received on:

07/01/2017

Accepted for publication:

25/03/2017

Received after proof reading:

06/05/2017

\section{INTRODUCTION}

Foot ulcers due to peripheral neuropathy or peripheral vascular disease and in combination of both seen in diabetic patients. ${ }^{1}$ The infection, depth, size and duration of wound also involved in impaired healing. These all factors lead to nonhealing and amputation of foot. ${ }^{2-4}$ The wound healing needs collagen synthesis and recovery of muscle injury. ${ }^{5}$

One of the most important factor is nutrition, which improves repair of soft tissue injuries and wound healing. ${ }^{6}$ Specific nutrients have been shown to enhance wound healing. ${ }^{7}$

Some studies have shown that wound healing enhanced by supplementation with the combination of arginine, glutamine and $\beta$-hydroxy- $\beta$-methyl butyrate which increases

\section{Dr. Imran Ali Shaikh', Dr. Naila Masood ${ }^{2}$, Dr. Fouzia Aijaz Shaikh ${ }^{3}$, Dr. Munir A Shaikh ${ }^{4}$} Private clinics of consultants of Hyderabe to June 2016. Methodology: 387 diabetic type 2 patients were selected from different clinics physicians, orthopedics and diabetic consultants of sadder Hyderabad Sindh Pakistan. The ulcers. Nutritional status was classfied on Mini Nutrit divided into three groups according to Mini nutritional score. Blood samples were obtained for Hemoglobin\%, blood sugar, serum calcium and serum albumin estimation. All patients were was considered statically significant. Results: There was linear correlation in between Mini valu). Conclusion: Diabetic foot ulcers are common in type 2 diabetic patients and nutritional status is strongly associated with grade of severity. It is important to assess nutritional Key words: Nutrition, diabetic, foot ulcer, Hyderabad, Sindh.

\section{Article Citation: Shaikh IA, Masood N, Shaikh FA, Shaikh MA. Diabetic foot ulcers; correlation of nutritional status of type 2 diabetic patients of Hyderabad Sindh, Pakistan. Professional Med J 2017;24(5):707-712. DOI: 10.17957/TPMJ/17.3869}

Diabetic foot ulcer is one of the commonest problems in medical practice. Foot ulcers are a source of major morbidity and also increase considerable financial burden on patient and families.

More than $15 \%$ of diabetic patients during their lives experience foot ulcers. ${ }^{8}$ These ulcers contributed more than $80 \%$ of non-traumatic lower limb amputations. ${ }^{9}$

As the diabetes advances, BMI, nutritional indicators (hemoglobin, serum albumin, total cholesterol) deteriorated gradually. Moreover, these nutritional indicators will more worse in patients with Wagner grade 4 and 5 ulcers. 
One study shown that the treatment of diabetic foot ulcers focused not only on pharmacological agents but also improvement in nutritional status. ${ }^{10}$

Low serum albumin concentrations and BMI were independent nutritional indicators, associated with mortality, frequency of dialysis and other possible complications in diabetic nephropathy. ${ }^{11}$

Diabetic foot ulcer needs good nutrition and albumin is very good indicator. ${ }^{12}$ Multiple studies have shown $3-4 \%$ diabetic patients have septic foot ulcer. $^{13}$

Prevalence studies of diabetes in Pakistan conducted by Shera et al shown prevalence of type 2 Diabetes among the adult population (>25 years) was $13.9 \%$ in Sindh and $8.6 \%$ in Baluchistan.

The gender distribution was $11.1 \%$ male and $13.4 \%$ female with impaired glucose tolerance (IGT) in the two provinces. ${ }^{14}$

There were over 7 million cases of diabetes in Pakistan in 2015 and prevalence is 6.9. ${ }^{15}$

The rationale of our study is to correlate the nutritional status to grade of diabetic foot ulcers as the impaired nutritional status is a major contributory in diabetic foot ulcers.

\section{MATERIAL AND METHODS}

This study was conducted by a team of two physicians, one statician and one junior doctor for filling Performa. This cross sectional study was included 387 patients from different clinics of sadder Hyderabad, Sindh, Pakistan.

The sample size was calculated by taking prevalence of diabetes in Pakistan was $6.9 \%$ in Pakistan in2105, confidence level 95\%. Sampling technique was non probability convenience.

The inclusion criteria were diabetic foot ulcer first time in life in either gender and age range was 3070 years. Out of 387,130 were females (33\%) and 257 were males (66.4\%). The exclusion criteria were immunological, traumatic or vascular ulcers because of non diabetic causes, and already diagnosed diabetic foot ulcers. Foot Ulcers under age of 30 years also been excluded. The mean duration of study was 16 months from February 2015 to June 2016.

A proper questionnaire was used to collect bio data from all patients along with duration of diabetes. Through clinical examination including general physical, sensory, motor examinations of feet and grading of foot ulcer was done.

Blood samples were collected included hemoglobin\%, albumin and calcium in $5 \mathrm{cc}$ disposable syringe and send to different laboratories of sadder. Random blood glucose was done on Medisign glucometer.

All foot ulcers were categorized according to WEGNER-MEGITT classification.

\begin{tabular}{|l|l|}
\hline \multicolumn{2}{|c|}{ Wagner-Meggitt Classification Of Diabetic Foot } \\
\hline G0 & Foot symptoms only like pain \\
\hline G1 & Superficial ulcer \\
\hline G2 & Deep ulcer \\
\hline G3 & Ulcer with bone involvement \\
\hline G4 & Fore foot ulcer \\
\hline G5 & Full foot ulcer \\
\hline
\end{tabular}

Assessment of nutritional status

Nutritional status was recorded on Mini Nutritional Assessment (MNA) Nestle Nutritional institute which contains screening; self questions and scales to assess adult nutrition. It contains three degrees of nutrition according to obtained score, $<17$ malnourished, $17-23.5$ risk of malnutrition $>$ 24 is normal status.

Base line demographic characteristics were noted, were including age, sex, BMI and duration of diabetes.

307 patients out of 387 were undergone for $x$ ray of affected foot. The radiological changes were consisting of soft tissue swelling, erosions, proximal bone involvement and Osteomyelitis.

Data were expressed as the mean and standard 
error (continuous variables) or as a number and percentage (categorical variables).

Comparisons of means and proportions were performed with an ANOVA. The homogeneity of groups was determined when the means had significant differences.

Multiple stepwise regression analysis was conducted to examine the main factors affecting nutrition status. SPSS 16.0 for Windows was used for all analyses. $\mathrm{P}<0.05$ was considered statistically significant.

\section{RESULTS}

387 patients were enrolled after proper consent, examination, biochemical and radiological investigation. All patients were assessed on two scales; Wegener grading for foot ulcer and Mini nutritional assessment scale.
The mean age and duration of diabetes was $40.5 \pm 11.5$ and $5 \pm 7.8$ years. Most of these patients had poor blood glucose control, mean random blood sugar was $255 \pm 27 \%$.

Wagner grade 4 and 5 ulcers had significantly lower hemoglobin, and serum albumin levels $p<$ 0.05 , and $<0.04$.while serum calcium was not associated to severity of ulcer $p>0.07$.

Poor control of diabetes was significantly correlated with degree of ulcer $(p<0.04)$ (Table-I).

There was linear correlation in between Mini nutritional assessment and severity of ulcer. Patients mini nutritional assessment score was $<17$ having more severe ulcer $p<0.03$ (Table-II).

Malnutrition was also associated with more severe radiological changes (Table-III).

\begin{tabular}{|l|c|c|c|c|c|c|c|}
\hline \multicolumn{1}{|c|}{ Variables } & G0 & G1 & G2 & G3 & G4 & G5 & P value \\
\hline Age & $35 \pm 5.6$ & $41 \pm 6.2$ & $52 \pm 5.5$ & $50 \pm 4.7$ & $55 \pm 4.5$ & $57 \pm 5.7$ & \\
\hline Male & 40 & 60 & 50 & 50 & 30 & 27 & \\
\hline Female & 20 & 25 & 20 & 40 & 20 & 10 & \\
\hline BMI & $29 \pm 3.5$ & $28 \pm 4.2$ & $29 \pm 3.7$ & $27 \pm 2.9$ & $24 \pm 4.8$ & $23 \pm 4.7$ & \\
\hline Duration of Diabetes & $2.5 \pm 2.5$ & $5 \pm 3.5$ & $6 \pm 3.5$ & $5 \pm 4.1$ & $8 \pm 2.6$ & $10 \pm 2.5$ & 0.06 \\
\hline Serum albumin & $4.1 \pm 1.2$ & $4.1 \pm 1.2$ & $3.5 \pm 1.9$ & $3.3 \pm 2.4$ & $3.1 \pm 1.2$ & $2.8 \pm 1$ & 0.04 \\
\hline Blood sugar & $250 \pm 44$ & $255 \pm 40$ & $290 \pm 43.2$ & $270 \pm 23.9$ & $273 \pm 26.7$ & $277 \pm 25.6$ & 0.05 \\
\hline Hemoglobin & $12.5 \pm 1$ & $12 \pm 1.4$ & $12.5 \pm 1.4$ & $11.4 \pm 1.8$ & $10.4 \pm 2.3$ & $11.2 \pm 2.5$ & 0.05 \\
\hline calcium & $9.5 \pm 1.7$ & $9 \pm 2.1$ & $9.1 \pm 2.1$ & $8.6 \pm 2.8$ & $9 \pm 1.9$ & $8.5 \pm 3.1$ & 0.07 \\
\hline
\end{tabular}

Table-I. Demographic and biochemical analysis of 387 patients

\begin{tabular}{|l|c|c|c|c|c|c|c|}
\hline \multicolumn{1}{|c|}{ MNA } & G0 & G1 & G2 & G3 & G4 & G 5 & P VALUE \\
\hline$<17$ & 2 & 10 & 12 & 20 & 25 & 21 & 0.03 \\
\hline $17-23.5$ & 10 & 25 & 35 & 20 & 25 & 15 & 0.05 \\
\hline$>23.5$ & 45 & 50 & 25 & 30 & 10 & 7 & 0.06 \\
\hline Total & 57 & 85 & 72 & 70 & 60 & 43 & \\
\hline
\end{tabular}

Table-II. Mini nutritional assessment of 387 patients correlated to grade of ulcer

\begin{tabular}{|l|c|c|c|}
\hline \multicolumn{1}{|c|}{ X ray findings } & MNA $>\mathbf{2 3 . 5}$ & $\mathbf{1 7 - 2 3 . 5}$ & $<\mathbf{1 7}$ \\
\hline Soft tissue swelling & 20 & 50 & 110 \\
\hline Erosions & 4 & 15 & 24 \\
\hline Sublaxation/fracture & 4 & 10 & 10 \\
\hline Osteomyelitis & 7 & 10 & 43 \\
\hline
\end{tabular}

Table-III. 307 patients with radiological changes according to mini nutritional assessment score

\section{DISCUSSION}

Diabetic foot disease effects $15 \%$ of the diabetic patients. The diabetic patients are 15 times more likely to under gone lower extremity amputation than their non diabetic. ${ }^{16}$

In Pakistan with an approximate population of 160 million, the incidence of diabetic foot ulcer is 
$10 \% .{ }^{17}$

In our study the mean age and duration of Diabetes was $47 \pm 11.5$ years, respectively and age range was 30-70 years, which was comparable to study done by Oyibo et $\mathrm{al}^{18}$, shown mean age of patients was 58.09 years, range of age was 29 to 78 years.

Gender distribution $59.7 \%$ were male which is matched to our study where male dominated $66 \%$. It was also reported by Veves et $\mathrm{al}^{19}$ with same age and sex distribution.

Sohn et at $a^{20}$ reported a significant J-shaped association between BMI and diabetic foot ulcers in addition Yekta et ${ }^{21}$ al also reported that a BMI less than 25 was significantly associated with amputation. In our study BMI was significantly associated with severity of ulcer, BMI 29 was associated to Grade 1 ulcer and low BMI 23 with grade 5 foot ulcer.

Malnutrition was identified in $62 . \%$ of the studied patients and malnutrition at presentation was predictive of poor outcome. ${ }^{22}$ In our study patients were categorized according to Mini Nutritional Assessment, score less than 23.5 was associated with advanced foot ulcers, score $<17$ was associated with significant $p$ value $<0.03$ and score in between 17-23.5, $p$ value was 0.05 .

Gau-BR et $\mathrm{al}^{23}$ were identified patients at risk of malnutrition (70.5\%) or malnourished (14.6\%) (Mean MNA score, 20.6 \pm 3.4 ).

Mini Nutritional Assessment score decreased with increasing severity of leg amputations; $p$ for linear trend $<0.001 .{ }^{24}$ In our study the risk of malnutrition was $33.5 \% p$ value was $<0.05$ while malnutrition observed in $23 \% p<0.03$.

Receiver operating characteristic analysis determined a hemoglobin cutoff of $12.3 \mathrm{~g} / \mathrm{dl}$ (females) and $12.1 \mathrm{~g} / \mathrm{dl}$ (males) to identify a highrisk population of diabetic foot ulcer patients who would have adverse outcomes. ${ }^{25}$ So anemia is common in patients with diabetic foot ulcer. Although typically mild or moderate, anemia has been associated with substantial morbidity and mortality in patients with diabetic foot ulcer.

In our study the mean hemoglobin was $12 \mathrm{~g} / \mathrm{dl}$. The correlation of anemia to diabetic foot ulcer was significant in our study $p$ value $<0.05$

In north India, Shahi SK ${ }^{26}$ et al shown diabetic foot ulcers grading, the percentage of grade3 lesion was highest (31.06\%) followed by grades 2 and 5 .

In our study Grade 3 -5 lesions was $45 \%$ while most common lesion was grade 1 ulcer This bias was might be early treatment seeking behavior in certain areas of our region, Hyderabad.

Naymu Pn et al shown in Nairobi that Wagner stage 2 ulcers were the commonest (49.4\%). ${ }^{27}$

The incidence of ulcer was highest (100\%), followed by cellulitis (97.93\%) and gangrene $(14.43 \%){ }^{28}$ Further assessment revealed that $56.70 \%$ of patients had limb-threatening ulcers while $43.29 \%$ had non-limb-threatening ulcers shown by Manda V. ${ }^{29}$

In our study $36.6 \%$ had $\mathrm{Gl}$ and 2 ulcer and only $26 \%$ had foot threatening ulcers it could because our patients were younger than the patients were selected by Manda V.

\section{CONCLUSION}

Diabetic foot ulcers are common and need full assessment. In many parts of underdeveloped countries it is uncommon to assess the nutritional status.

Our study clearly shown the strong relationship of nutrition to severity of diabetic foot ulcers. The good parameters of nutrition are BMI, serum albumin and hemoglobin. The appropriate scale for nutritional status of adult is mini nutritional assessment scale.

Copyright @ 25 Mar, 2017.

\section{REFERENCES}

1. Mills JL, Conte MS, Armstrong DG, Pomposelli FB, Schanzer A, Sidawy AN et al. The society for vascular surgery lower extremity threatened limb 
classification system: risk stratification based on wound, ischemia, and foot infection (WIfl). J Vasc Surg 2014; 59:220-234.

2. Armstrong DG, Lavery LA, Harkless LB. Validation of a diabetic wound classification system. The contribution of depth, infection and ischemia to risk of amputation. Diabetes Care 1998; 21: 855-859.

3. Oyibo SO, Jude EB, Tarawneh I, Nguyen HC, Harkless LB, Boulton AJ. A comparison of two diabetic foot ulcer classification systems: the Wagner and the University of Texas wound classification systems. Diabetes Care 2001; 24: 84-88.

4. Oyibo SO, Jude EB, Tarawneh I, Nguyen HC, Armstrong $D G$, Harkless LB et al. The effects of ulcer size and site, patient's age, sex and type and duration of diabetes on the outcome of diabetic foot ulcers. Diabet Med 2001; 18: 133-138.

5. Williams JZ, Abumrad N, Barbul A. Effect of a specialized amino acid mixture on human collagen deposition. Ann Surg 2002; 236:369-375

6. Himes D. Protein-calorie malnutrition and involuntary weight loss: the role of aggressive nutritional intervention in wound healing. Ostomy Wound Manag 1999; 45: 46-51.

7. Litchford M. Nutritional issues in the patient with diabetes and foot ulcers. In: Bowker JH, Pfeifer MA eds. Levin and O'Neal's The Diabetic Foot, 7th ed. Philadelphia: Mosby Elsevier, 2008: 199-217

8. Singh N, Armstrong DG, Lipsky BA. Preventing foot ulcers in patients with diabetes. JAMA 2005; 293: 217-228.

9. Pecoraro RE, Reiber GE, Burgess EM. Pathways to diabetic limb amputation. Basis for prevention. Diabetes Care 1990; 13:513-521.

10. Yang W, Lu J, Weng J, et al: Prevalence of diabetes among men and women in China. $\mathrm{N}$ Engl $\mathrm{J}$ Med. 362:1090-1101. 2010

11. Yekta Z, Pourali R, Nezhadrahim R, Ravanyar L and Ghasemi-Rad M: Clinical and behavioral factors associated with management outcome in hospitalized patients with diabetic foot ulcer. Diabetes Metab Syndr Obes. 4:371-375. 2011

12. Litchford $M$. Nutritional issues in the patient with diabetes and foot ulcers. In: Bowker JH, Pfeifer MA, editors. Levin and O'Neal's The Diabetic Foot. 7th ed. Philadelphia: Mosby Elsevier; 2008. pp. 199-217.

13. National Diabetes Data Group (U.S.). Diabetes in
America. 2nd ed. Bethesda, MD: National Institute of Diabetes and Digestive and Kidney Diseases; 1995.p. 95-1468.

14. Shera AS, Ratiquc G, Khawaja IA, et al. Pakistan National Diabetes Survey; prevalence of glucose intolerance and associated factors in Baluchistan Province. Diabetes Res. Clin. Prac., 1999: 44:49-58

15. IDF middle east and north Africa 2015.

16. WB. Classification of foot lesions in Diabetic patients. Levin and O'Neal's The Diabetic Foot. 2008;9:221-226

17. Dorresteijn JAN, Kriegsman DMW, Assendelft WJJ, Valk GD. Patient education for preventing diabetic foot ulceration. Cochrane Database of Systematic Reviews 2010, 5. Art. No.CD001488. DOI: 10.1002/14651858. CD001488.pub3.

18. Mehmood K, Akhtar T, Talib A, Abbasi B, Salakeen SU, $\mathrm{NaqvilH}$. Clinical profile and management outcome of diabetic footulcer in a tertiary care hospital. J Coll Physicians Surg Pak2008; 18:408-12.

19. Oyibo SO, Jude EB, Tarawneh I, Nguyen HC, Armstrong DG, Harkless LB, et al. The effects of ulcer size and site, patient'sage, sex and type and duration of diabetes on the outcome of diabetic foot ulcers. Diabet Med 2001; 18(2):133-8.

20. A VevesH. J. MurrayM. J. Young etal: The risk of foot ulceration in diabetic patients with high foot pressure: a prospective study DiabetologiaJuly 1992, Volume 35 , Issue 7, pp 660-663

21. Sohn MW, Budiman-Mak E, Lee TA, Oh E, Stuck RM. Significant J-shaped association between body mass index (BMI) and diabetic foot ulcers. Diabetes Metab Res Rev. 2011; 27:402-409.

22. Yekta Z, Pourali R, Nezhadrahim R, Ravanyar L, GhasemiRad M. Clinical and behavioral factors associated with management outcome in hospitalized patients with diabetic foot ulcer. Diabetes Metab Syndr Obes. 2011;4:371-375

23. Bedilu Deribe, Kifle Woldemichael and Gugsa Nemera; Prevalence and Factors Influencing Diabetic Foot Ulcer among Diabetic Patients Attending Arbaminch Hospital, South Ethiopia Journal of Diabetes \& Metabolism. January 05, 2014

24. Shan-shan zhang, zheng-yi tang, Ping fang etal; Nutritional status deteriorates as the severity of diabetic foot ulcers increases and independently associates with prognosis. Exp Ther Med. 2013 Jan; 5(1): 215-222 
25. Gau BR, Chen HY, Hung SY, Yang HM et al; The impact of nutritional status on treatment outcomes of patients with limb-threatening diabetic foot ulcers. $J$ Diabetes Complications. 2016 Jan-Feb; 30(1):138-42. . Epub 2015 Sep 26.

26. Fengning Chuan, MD1, Min Zhang, MD1, Yang Yao et al; Anemia in Patients With Diabetic Foot Ulcer, Prevalence, Clinical Characteristics, and Outcome; International journal of Lower extremity wounds 15:220-226, sept 2016

27. Nyamu PN, Otieno CF, Amayo EO, McLigeyo so (2003) Risk factors and prevalence of diabetic foot ulcers at Kenyatta National Hospital, Nairobi. East Afr
Med J 80: 36-43.

28. Shahi SK, Kumar A, Kumar S, Singh SK, Gupta SK, et al. (2012) Prevalence of Diabetic Foot Ulcer and Associated Risk Factors in Diabetic Patients From North India. The Journal of Diabetic Foot Complications 4: 83-91.

29. Manda V, Sreedharan J, Muttappallymyalil J, Das R, Hisamatsu E (2012) Foot ulcers and risk factors among diabetic patients visiting Surgery Department in a University Teaching Hospital in Ajman, UAE. International Journal of Medicine and Public Health 2: 34-38.

\section{PREVIOUS RELATED STUDY}

Altaf Hussain Rathore. DIABETIC FOOT. (Editorial) Prof Med Jour 16(4) 472-474 Oct, Nov, Dec 2009.

Haji Khan Khoharo, Shuaib Ansari, Fatima Qureshi. DIABETIC FOOT ULCERS (Original) Prof Med Jour 16(1) 49 53 an, Feb, Mar 2009.

Johar Ali, Ali Akbar, Waqas Anwar. DIABETIC FOOT ULCER GRADES; CORRELATION WITH ANKLE BRACHIAL PRESSURE INDEX (Original) Prof Med Jour 15(1) 133 - 136 Jan, Feb, Mar, 2008.

G. M. Khan Baloch, Khalid Hussain Qureshi, Asim Bhatti. DIABETIC FOOT; SURGICAL MANAGEMENT. (Original) Professional Med J Jan-Feb 2012;19(1): 006-010.

\section{AUTHORSHIP AND CONTRIBUTION DECLARATION}

\begin{tabular}{|c|c|c|c|}
\hline Sr. \# & Author-s Full Name & Contribution to the paper & Author $=\mathbf{s}$ Signature \\
\hline 1 & Dr. Imran Ali Shaikh & $\begin{array}{l}\text { Hypothesis, critical analysis } \\
\text { \& final version of manuscript }\end{array}$ & \\
\hline 2 & Dr. Naila Masood & Writing manuscript & \\
\hline 3 & Dr. Fouzia Aijaz Shaikh & Collection of cases & \\
\hline 4 & Dr. Munir A Shaikh & Statistical analysis & \\
\hline
\end{tabular}

